\title{
Lactobacillus GG in inducing and maintaining remission of Crohn's disease
}

\author{
Michael Schultz*1, Antje Timmer ${ }^{1}$, Hans H Herfarth ${ }^{1}$, R Balfour Sartor ${ }^{2}$, \\ Jon A Vanderhoof ${ }^{3}$ and Heiko C Rath ${ }^{1}$
}

\begin{abstract}
Address: ${ }^{1}$ Department of Internal Medicine I, University of Regensburg, Regensburg, Germany, ${ }^{2}$ University of North Carolina at Chapel Hill, School of Medicine, Department of Digestive Diseases, Chapel Hill, NC, USA and ${ }^{3}$ University of Nebraska at Omaha, School of Medicine, Department of Pediatrics, Omaha, NE, USA

Email: Michael Schultz* - michael.schultz@klinik.uni-regensburg.de; Antje Timmer - antje.timmer@klinik.uni-regensburg.de; Hans H Herfarth - hans.herfarth@klinik.uni-regensburg.de; R Balfour Sartor - rbs@med.unc.edu; Jon A Vanderhoof - jvanderh@unmc.edu; Heiko C Rath - heiko.rath@klinik.uni-regensburg.de

* Corresponding author
\end{abstract}

Published: 15 March 2004

BMC Gastroenterology 2004, 4:5
Received: 12 September 2003

Accepted: 15 March 2004

This article is available from: http://www.biomedcentral.com/I47I-230X/4/5

(c) 2004 Schultz et al; licensee BioMed Central Ltd. This is an Open Access article: verbatim copying and redistribution of this article are permitted in all media for any purpose, provided this notice is preserved along with the article's original URL.

\begin{abstract}
Background: Experimental studies have shown that luminal antigens are involved in chronic intestinal inflammatory disorders such as Crohn's disease and ulcerative colitis. Alteration of the intestinal microflora by antibiotic or probiotic therapy may induce and maintain remission. The aim of this randomized, placebo-controlled trial was to determine the effect of oral Lactobacillus GG ( $L$. GG) to induce or maintain medically induced remission.
\end{abstract}

Methods: Eleven patients with moderate to active Crohn's disease were enrolled in this trial to receive either $L$. GG $\left(2 \times 10^{9} \mathrm{CFU} /\right.$ day $)$ or placebo for six months. All patients were started on a tapering steroid regime and received antibiotics for the week before the probiotic/placebo medication was initiated. The primary end point was sustained remission, defined as freedom from relapse at the 6 months follow-up visit. Relapse was defined as an increase in CDAI of $>100$ points.

Results: $5 / 1$ I patients finished the study, with 2 patients in each group in sustained remission. The median time to relapse was $16 \pm 4$ weeks in the $L$. GG group and $12 \pm 4.3$ weeks in the placebo group $(p=0.5)$.

Conclusion: In this study we could not demonstrate a benefit of $L$. GG in inducing or maintaining medically induced remission in CD.

\section{Background}

Chronic inflammatory bowel diseases (IBD) such as Crohn's disease (CD) and ulcerative colitis (UC) appear to be the result of an unbalanced immune response to luminal antigens. There is evidence from clinical trials and animal experiments that alteration of the composition of the intestinal microflora by antibiotic treatment can induce and maintain remission [1].
Recently, probiotic microorganisms received much scientific attention due to reports of successful treatment of various intestinal, mainly infectious disorders [2]. Furthermore, there are reports on successful induction and maintenance of remission of chronic pouchitis [3] and ulcerative colitis [4], but treatment of Crohn's disease with probiotic preparations proved difficult [5-7]. While L. GG and E. coli strain Nissle 1917 were ineffective in 


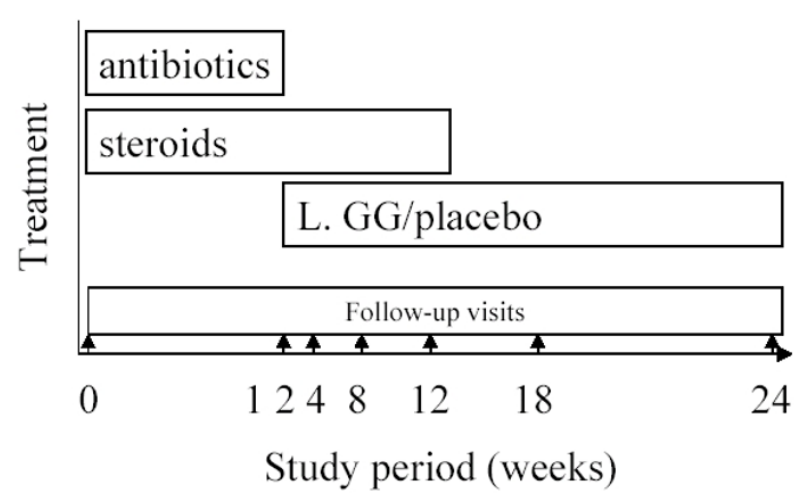

Figure I

Outline of the study protocol

preventing recurrence after curative resection in $\mathrm{CD}$ or maintaining medically induced remission $[5,6]$, the probiotic compound VSL\#3 together with antibiotic therapy was beneficial in prevention of post-operative recurrence of Crohn's disease [8], and $L$. GG led to a significant clinical improvement in pediatric CD patients [7], but no clinical trials were performed to test the ability to maintain a medically induced remission in adult CD.

The mechanisms by which probiotic microorganisms mediate their therapeutic effects are not fully understood. Probiotic microorganisms exert their action through a temporary modulation of the intestinal bowel flora $[9,10]$ and by that might influence the intestinal immune system $[11,12]$. In vitro, lactobacilli induce the secretion of a variety of cytokines [13-16], and in vivo, these microorganisms appear to shift a Th1-mediated immune response to intestinal bacteria to a Th-2-dominated response $[11,12]$. Since especially CD appears to be a Th1-driven disease, with an overly aggressive immune response to the intestinal microflora, probiotics should theoretically be able to alter the course of the disease $[17,18]$.

The aim of this study was therefore to evaluate the effect of oral $L$. GG on induction and maintenance of remission in patients with moderate to active $\mathrm{CD}$.

\section{Methods \\ Patients}

A total of 11 patients were with moderate to active Crohn's disease (CDAI 150-300) were enrolled in this randomized, double-blind, placebo-controlled trial. The ethical review panel of the University of Regensburg, School of Medicine approved the study protocol and informed consent was obtained prior to enrollment in the trial. At the beginning of the study, both groups were com-

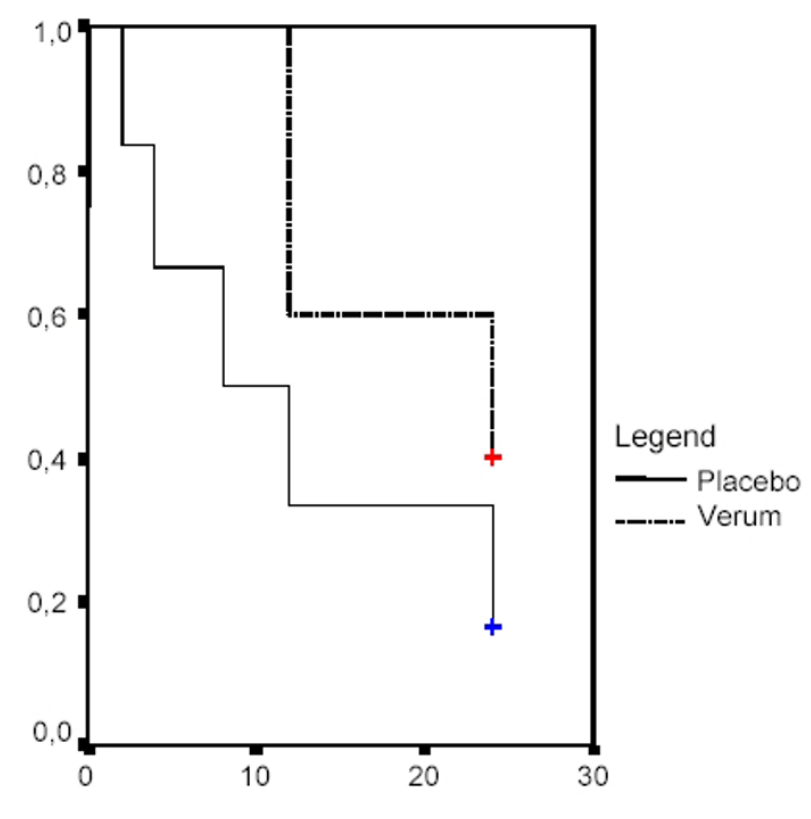

Time to relapse

(in weeks)

Figure 2

Time to relapse as depicted by Kaplan-Meier survival estimates.

parable in demographic characteristics (age, gender), in CDAI $(269 \pm 44$ vs. $304 \pm 27)$, and c-reactive protein (CRP; $32 \mathrm{mg} / \mathrm{l} \pm 11 \mathrm{mg} / \mathrm{l}$ vs. $54 \mathrm{mg} / \mathrm{l} \pm 21 \mathrm{mg} / \mathrm{l}$ ).

\section{Treatment protocol}

The study profile is outlined in Figure 1. Following baseline examination to determine eligibility, all patients were started on oral antibiotic treatment (ciprofloxacin $500 \mathrm{mg}$ bd, metronidazole $250 \mathrm{mg}$ tds) to be continued for 2 weeks. Following week 1 , the patients were randomized to receive either L. GG $(\mathrm{n}=5)\left(2 \times 10^{9} \mathrm{CFU} /\right.$ day; CAG Functional Foods, Omaha, NE) or placebo $(n=6)$. The probiotic therapy was continued for 6 months.

For the first 12 weeks, a standard tapering regime of corticosteroids, beginning with $60 \mathrm{mg}$ p.o. per day was administered. Follow up visits were carried out after 2, 4, 8, 12, 18 weeks and after 6 months.

\section{Statistical analysis}

The primary end point was reached at 6 months in sustained remission or at time of relapse. Secondary end points were tolerability, possible side effects of the study medication and impact on c-reactive protein. Relapse was defined as an increase in CDAI of $>100$ points. Statistical 
Table I: Study characteristics

\begin{tabular}{llllllll}
\hline & pts. & CDA* & CRP* in mg/l & remission & sustained remission & Relapse & mean time to relapse (in weeks) \\
\hline L. GG & $\mathrm{n}=5$ & $269 \pm 44$ & $32 \pm 11$ & $4 / 5$ & $2 / 4$ & $2 / 4$ & $16 \pm 4$ \\
Placebo & $\mathrm{n}=6$ & $304 \pm 27$ & $54 \pm 21$ & $5 / 6$ & $2 / 5$ & $3 / 5$ & $12 \pm 4.3^{* *}$ \\
\hline
\end{tabular}

$*_{\text {at }}$ time of recruitment $* *_{\mathrm{ns}}$

analyses were performed using a test for normality, followed by a t-test or a Mann-Whitney Rank Sum Test. The probability for relapse was calculated using the KaplanMeier method (SPSS for windows, Version 11.0).

Due to slow inclusion rates and negative reports of the effect of L. GG in maintenance of remission in CD, the enrolment of patients was stopped prematurely, resulting in a small study population.

\section{Results}

Apart from mild bloating, no significant side effects were reported.

A total of 11 patients were enrolled into the trial. 5/11 patients finished the study period, with 2 patients in each group in sustained remission (table 1). Four patients in the verum group and 5 patients in the placebo group reached remission during the observation period but 2 patients receiving $L$. GG and 3 patients on placebo relapsed.

In the verum group, 2 patients had signs of a clinical relapse in week 12, and 1 patient still had active disease at the end of the trial. One of the patients with signs of a clinical relapse developed an intestinal abscess, but no $L$. GG could be identified by culture.

In the placebo arm, 2 patients showed signs of a relapse in week 4 and respectively in week 8 , while another patient relapsed in week 12. One patient had to be taken out of the trial due to ileocaecal resection in week 8 .

The mean time to relapse was $16 \pm 4$ weeks in the $L$. GG group and $12 \pm 4.3$ weeks in the placebo group $(\mathrm{p}=0.5)$ (Fig. 2). All other parameters (CDAI, CRP) were not altered in both groups.

\section{Discussion}

There is mounting evidence from clinical trials and animal studies, demonstrating the beneficial effects of probiotic preparations in the treatment chronic intestinal disorders such as ulcerative colitis and pouchitis. However, in Crohn's disease, there are conflicting reports in the literature. Saccharomyces boulardii and the probiotic preparation VSL\#3 were promising in clinical trials in the main- tenance of medically or surgically induced remission of CD [19-21], but E. coli Nissle 1917 was not beneficial in Crohn's disease [5]. Gupta et al. conducted a small open trial using L. GG in children with Crohn's disease and was able to document clinical improvement [7]. However, in a larger follow-up study, Bousvarous et al. were not able to show an effect of adding L. GG to standard maintenance therapy in children with Crohn's disease [21]. In a recent trial by Prantera et al. $L$. GG was added to postoperative treatment to maintain remission in Crohn's disease with no clinical benefits seen [6].

In our trial, we could not demonstrate a benefit of $L$. GG in inducing remission in $\mathrm{CD}$. While this observation could be due to the short observation period of six months, in 2/5 patients of the L. GG group, relapse occurred in week 12, at the end of the tapering steroid medication. This was also seen in the placebo group, where two patients relapsed at week 4 or respectively week 8 and therefore is probably due to the fact of reducing the steroid medication. Only $1 / 5$ patients in the placebo arm went into remission and relapse at the end of the study period. $2 / 5$ patients receiving $L$. GG and $2 / 6$ patients in the placebo group achieved and maintained remission. Due to the small sample size and 1 patient not finishing the trial in the placebo arm, we are not able to comment on the effect of $L$. GG to maintain remission once the steroid medication had ceased.

\section{Conclusions}

In this study we could not demonstrate a benefit of $L$. GG in inducing or maintaining medically induced remission in $\mathrm{CD}$.

\section{Competing interests}

None declared.

\section{Authors' contributions}

M.S., H.H.H. and H.C.R. were the primary investigators in this clinical trial, drafted the protocol and enrolled the patients.

R.B.S. and J.A.V. reviewed the study protocol.

A.T. performed the statistical analysis. 


\section{Acknowledgements}

This study was in part supported by the Deutsche Morbus Crohn und Colitis ulcerosa Vereinigung e.V. (DCCV).

\section{References}

I. Schultz M, Scholmerich J, Rath HC: The role of antibiotic and probiotic therapy in inflammatory bowel diseases. Dig Dis Sci 2003, 2I:105-128.

2. Isolauri E: Probiotics for infectious diarrhea. Gut 2003, 52:436-437.

3. Gionchetti P, Rizzello F, Venturi A, Brigidi P, Matteuzzi D, Bazzocchi G, Poggioli G, Miglioli M, Campieri M: Oral bacteriotherapy as maintenance treatment in patients with chronic pouchitis: a double-blind, placebo-controlled trial. Gastroenterology 2000, I 1 9:305-309.

4. Kruis W, Fric P, Stolte M, The Mutaflor Study Group: Maintenance of remission in ulcerative colitis is equally effective with Escherichia coli Nissle 1917 and with standard mesalamine. Gastroenterology 200I, I 20:680.

5. Malchow HA: Crohn's disease and Escherichia coli. A new approach in therapy to maintain remission of colonic Crohn's disease? J Clin Gastroenterol 1997, 25:653-658.

6. Prantera C, Scribano ML, Falasco G, Andreoli A, Luzi C: Ineffectiveness of probiotics in preventing recurrence after curative resection for Crohn's disease: a randomised controlled trial with Lactobacillus GG. Gut 2002, 5 I:405-409.

7. Gupta P, Andrew H, Kirschner BS, Guandalini S: Is Lactobacillus GG helpful in children with Crohn's disease? Results of a preliminary, open-label study. I Pediatr Gastroenterol Nutr 2000 3 I:453-457

8. Campieri M, Rizzello F, Venturi A, Poggioli G, Ugolini F, Helwig U, Amasini C, Romboli E, Gionchetti P: Combination of antibiotic and probiotic treatment is efficacious in prophylaxis of postoperative recurrence of Crohn's disease: a randomized controlled study vs. mesalamine. Gastroenterology 2000, I I 8:4 I 79.

9. Tannock GW, Munro K, Harmsen HJ, Welling GW, Smart J, Gopal PK: Analysis of the fecal microflora of human subjects consuming a probiotic product containing Lactobacillus rhamnosus DR20. Appl Environ Microbiol 2000, 66:2578-2588.

10. Venturi A, Gionchetti P, Rizzello F, Johansson R, Zucconi E, Brigidi P, Matteuzzi D, Campieri M: Impact on the composition of the faecal flora by a new probiotic preparation: preliminary data on maintenance treatment of patients with ulcerative colitis. Aliment Pharm Therap 1999, I 3: I 103-I I08.

II. Ulisse S, Gionchetti P, D'Alò S, Russo FP, Pesce I, Ricci G, Rizzello F, Helwig U, Cifone MG, Campieri M, DeSimone C: Expression of cytokines, inducible nitric oxide synthetase and matrix metalloproteinases in pouchitis: effects of probiotic treatment. Am J Gastroenterol 2001, 96:2691-2699.

12. Schultz M, Linde HJ, Lehn N, Zimmermann K, Grossmann J, Falk W, Schölmerich J: Immunomodulatory consequences of oral administration of Lactobacillus rhamnosus strain GG (L. GG) in healthy volunteers. J Dairy Res 2003, 70:163-170.

13. Miettinen M, Vuopio-Varkila J, Varkila K: Production of human tumor necrosis factor alpha, interleukin-6, and interleukin10 is induced by lactic acid bacteria. Infect Immun 1996, 64:5403-5405

14. Miettinen M, Matikainen S, Vuopio-Varkila J, Pirhonen J, Varkila K, Kurimoto $M$, Julkunen I: Lactobacilli and streptococci induce interleukin-I 2 (IL-I 2), IL- I 8, and gamma interferon production in human peripheral blood mononuclear cells. Infect Immun 1998, 66:6058-6062.

15. Miettinen M, Lehtonen A, Julkunen I, Matikainen S: Lactobacilli and streptococci activate NF-kappa B and STAT signaling pathways in human macrophages. I Immunol 2000, 164:3733-3740.

16. Lammers KM, Helwig U, Swennen E, Rizzello F, Venturi A, Caramelli E, Kamm MA, Brigidi P, Gionchetti P, Campieri M: Effect of probiotic strains on interleukin-8 production by HT-29/19A cells. Am J Gastroenterol 2002, 97: I I 82- I I 86.

17. Guslandi M: Probiotics for Chronic Intestinal Disorders. Am J Gastroenterol 2003, 98:520-521.

18. Shanahan F: Turbo probiotics for IBD. Gastroenterology 200I, I 20:1297-1308.

19. Pein K, Hotz J: Therapeutic effects of Saccharomyces boulardii on mild residual symptoms in a stable phase of Crohn's dis- ease with special respect to chronic diarrhea - a pilot study. Z Gastroenterol 1993, 3 | : |29- I 34.

20. Guslandi M, Mezzi G, Sorghi M, Testoni PA: Saccharomyces boulardii in maintenance treatment of Crohn's disease. Dig Dis $\mathrm{Sci}$ 2000, 45:|462-|464.

21. Bousvarous K, The L. GG Study Group: A multicenter, placebocontrolled, double-blind study of Lactobacillus GG in addition to standard maintenance medication therapy in children with Crohn's disease. J Ped Gastroenterol Nutr 2002, 35:A7.

\section{Pre-publication history}

The pre-publication history for this paper can be accessed here:

http://www.biomedcentral.com/1471-230X/4/5/prepub
Publish with Biomed Central and every scientist can read your work free of charge

"BioMed Central will be the most significant development for disseminating the results of biomedical research in our lifetime. "

Sir Paul Nurse, Cancer Research UK

Your research papers will be:

- available free of charge to the entire biomedical community

- peer reviewed and published immediately upon acceptance

- cited in PubMed and archived on PubMed Central

- yours - you keep the copyright

Submit your manuscript here:

http://www.biomedcentral.com/info/publishing_adv.asp
BioMedcentral 